\title{
El remanente idealista en la razón pública que busca el «overlapping consensus» por mediación de un «veil of ignorance»
}

\section{Public reason, which seeks the "overlapping consensus» through the intervention of a "veil of ignorance», is marked with the remains of Idealism}

\author{
ALEJANDRO ROJAS JIMÉNEZ \\ Malaga Institute of Technology (España)
}

Recibido: 20-12-2013 Aceptado definitivamente: 10-03-2014

\section{RESUMEN}

Este trabajo busca establecer cuál es el remanente idealista de la razón pública que pervive en el intento infructuoso de superar el idealismo absoluto limitando la razón que debe encargarse de construir el consenso no-excluyente por superposición. Como alternativa se propone pensar un nuevo tipo de consenso, eventual e inestable, que exija- y aquí estaría latente el otro idealismo no absoluto del de Leonberg- una comunicación constante basada en el diálogo inagotable del que nazcan normas concretas de conducta consensuadas pero eventuales.

\section{PALABRAS CLAVES}

CONSENSUS EVENTUEL, KOMMUNIKATIVE VERNUNFT, RECEVABILITE, PUBLIC REASON. 


\begin{abstract}
This paper want to establish the idealist remains of public reason, showing that absolute idealism can not be overcome by limiting the reason, that must build the nonexclusionary consensus by overlapping, but instead proposing like aim a new type of consensus, eventual and unstable, which would require, and here would be latent the other non-absolute idealism of Leonberg, a constant communication based on infinite dialogue that giving cause for specific rules of conduct, agreed but reviewable.
\end{abstract}

\title{
KEY WORDS \\ CONSENSUS EVENTUEL, KOMMUNIKATIVE VERNUNFT, RECEVABILITE, PUBLIC REASON.
}

\section{INTRODUCCIÓN: JOHN RAWLS Y EL RETORNO DEL CONTRACTUALISMO}

La referencia en el título de este trabajo a una razón pública que busca un overlapping consensus por mediación de un veil of ignorance hace referencia, evidentemente, al recurso fundamental de Rawls ${ }^{1}$ de apelar a una original position que tuviere por función cegar a los individuos sobre todos los hechos acerca de sí mismos que pudieran nublar su noción de justicia. Este recurso surge desde el convencimiento de que las convicciones particulares deben ser excluidas de la discusión pública; ${ }^{2}$ relegadas a un ámbito privado. Y ello porque en sociedades plurales, marcadas por una diversidad de doctrinas religiosas, filosóficas y morales, o lo que es lo mismo given the fact of reasonable pluralism, ${ }^{3}$ debemos proceder según Rawls prescindiendo de las «razones sociales» (a menudo irreconciliables y opuestas entre sí), consideradas non public reasons ${ }^{4}$ (entre las que incluye desde luego a las generadas en universidades y asociaciones científicas ${ }^{5}$ ). De este modo Rawls es contundente: en lugar de un uso público de la razón práctica (aquella que tiene como objeto lo que depende de nosotros y, por consiguiente, puede ser distinto ${ }^{6}$ ), propone una razón que, para discutir de los fundamentos constitucionales y de las cuestiones básicas de justicia, prescinda de la

1 El filósofo estadounidense fue justamente reconocido con la National Humanities Medal en 1999 por contribuir a revivir la creencia en la capacidad de la democracia para construir una sociedad justa.

2 Aquella que tiene por propósito los fundamentos constitucionales y las cuestiones básicas de justicia.

3 «a democratic society is marked by the fact of reasonable pluralism», Cfr., Rawls, J., Political Liberalism, Nueva York, Columbia University Press, 1993, p. 36.

4 «nonpublic reasons comprise the many reasons of civil society and belong to what I have called the «background culture», in contrast with the public political culture», Political Liberalism, op. cit. p. 220.

5 «First of all, there are many nonpublic reasons and but one public reason. Among the nonpublic reasons are those os associations of all kinds: churches and universities, scientific societies and professional groups», Political Liberalism, op. cit., 220.

6 Ética a Nicómaco 1139 b 21-22 
background culture $e^{7}$ (también llamada cultura de la sociedad civil) y de toda convicción particular.

Rawls no duda en decir que su propuesta filosófica es highly kantian in natu$r e$. Y desde luego en algún sentido es así, puesto que también Kant había considerado que debemos proponer un criterio que no se rigiese por eines vorgesetzten Zweckes. ${ }^{8}$ Así, para Kant, der gute Wille es capaz de construir un orden justo precisamente en tanto que es capaz de dejar de lado las determinadas razones materiales y propósitos concretos.

Ahora bien, mientras que Kant considera que tenemos que actuar obedeciendo un Prinzip des Wollens subjetivo y formal, ${ }^{9}$ Rawls, considera sin embargo que el criterio formal kantiano del imperativo categórico debe ser reformulado después de observar que el principio kantiano es excluyente con respecto a aquellas motivaciones que no puedan convertirse en ley universal. La pretensión de Rawls es que no quede excluida ninguna motivación (o tan sólo aquellas que den lugar a formas de desigualdad injustas ${ }^{10}$ ), y por eso reformula el imperativo kantiano como sigue: actúa conforme a unos principios fundamentales de justicia que cualquier otro convendría en una posición original de igualdad. ${ }^{11}$

La cuestión debe ser bien enfocada: Rawls no dirige este imperativo a los ciudadanos corrientes, sino a los legisladores y los agentes del gobierno, los jueces y los miembros de los tribunales superiores de justicia. La cuestión es entonces que si no queremos que estos tomen decisiones que no respeten la capacidad de los ciudadanos para orientar sus vidas particulares siguiendo sus propias motivaciones de conducta (con exclusión -como decía- de aquellas que van contra la desigualdad justa y que quedarían fuera del overlapping consensus), entonces deberíamos exigirles, según Rawls, que procedieran sin querer favorecer intereses concretos, sino actuando desde aquella original position referida, ya que de este modo se garantizaría su compromiso con la libertad negativa.

Ahora bien, y aunque incluso Rawls se ve obligado a aceptar un mínimo de reflective equilibrium entre principios abstractos e intuiciones morales (juicios

7 En realidad esto debe ser matizado: Rawls asume que los ciudadanos comparten una tradición específica que se caracteriza por ver a los ciudadanos como agentes morales autónomos.

8 «Der gute Wille ist nicht durch das, was er bewirkt oder ausrichtet, nicht durch seine Tauglichkeit zur Erreichung irgend eines vorgesetzten Zweckes» Kant, I. Grundlegung zur Metaphysik der Sitten, Hamburg: Meiner, 1999, p. 394.

9 «handle nur nach derjenigen Maxime, durch die du zugleich wollen kannst, dass sie ein allgemeines Gesetz werde», Grundlegung zur Metaphysik der Sitten, op. cit. p 45

10 La noción de desigualdad justa debemos pensarla enlazando el incremento de la desigualdad con el mejoramiento de la suerte de los menos favorecidos.

11 J. Rawls, A Theory of Justice, Cambridge: Mass., Harvard University Press, 1971, 1999, pp 156-157. 
bien ponderados que encontramos en nuestra vida moral), lo cierto es que deja la puerta abierta a uno de los grandes peligros de nuestras sociedades libres actuales, a saber: no se les exige a los gobernantes un compromiso suficiente con la libertad positiva. ${ }^{12}$ Para entender bien este punto conviene prestar atención en primer lugar a lo que bien podríamos designar como el reto de la pluralidad, el cual enmarca decisivamente la cuestión.

\section{I.1. EL RETO DE LA PLURALIDAD}

Desde luego, la pluralidad quizás ahora sea más manifiesta que nunca (vemos en un día en un aeropuerto a más personas de distintos lugares de las que jamás vio un hombre de otra época en toda su vida ${ }^{13}$ ), pero no es en rigor un hecho nuevo que se dé una pluralidad de convicciones en torno a cómo debe cada uno vivir su vida. El reto de la pluralidad es un reto que ya intentaron afrontar otros autores del pasado como Kant o Hegel. Lo que sí es más novedoso es que se aluda a ella actualmente para argumentar que la libertad positiva no debe ser exigida porque pone supuestamente en peligro la convivencia en sociedades plurales. Da la impresión de que para muchos autores tenemos que optar entre la razón fuerte del despotismo ilustrado o una razón «débil» sin poder práctico de decisión. ${ }^{14}$ Se propone pues una razón pública que no sea ya aquella del Gelehrter que habla vor dem ganzen Publicum, ${ }^{15}$ y ello por considerar que el uso puro de la razón práctica como herramienta fundamental para construir el consenso tiene que ser evitada.

No es necesario sin embargo poner límites a la razón para construir una sociedad justa y libre. La razón fuerte no implica necesariamente dogmatismo, despotismo ni intolerancia: la razón puede dar lugar a un tipo de sociedad justa, libre y tolerante, porque el error nunca estuvo en rigor, como se pretenderá hacer ver, en su ejercicio fuerte, sino en cierta pretensión del idealismo absoluto que

12 Es uno de los aspectos, por ejemplo, a tener en cuenta para comprender la actual desconsideración de los gobernantes acerca de la asignatura de filosofía en los institutos de enseñanza públicos españoles.

13 Cfr., K.A. Appiah, 2006. Cosmopolitanism: Ethics in a world of strangers. New York: W. W. Norton and Co.

14 «la tarea de la reflexión teórica más general (que por abreviar llamamos filosófica) no es, como pensaban los ilustrados, despejar definitivamente las sombras que cubren el campo de la convivencia social; más modestamente, pretende $-o$ debería pretender- iluminar suficientemente el camino, con la luz de la experiencia comprendida, como para poder evitar los más peligrosos desvaríos.» José Monyoya, justicia, sociedad mercado, en Carracedo-RosalesToscano (eds). Retos pendientes en ética y política, Contrastes suplemento 5 (2000) 229-234, 234.

15 «Ich verstehe aber unter dem öffentlichen Gebrauche seiner eigenen Vernunft denjenigen, den jemand als Gelehrter von ihr vor dem ganzen Publicum der Leserwelt macht» Kant, I., «Beantwortung der Frage: Was ist Aufklärung (1784)», en Kleine Schriften VIII 37. 
curiosamente sigue como remanente en Rawls, a saber: la pretensión de un consenso permanente o stable. ${ }^{16}$

Si analizamos comparativamente la propuesta del despotismo ilustrado y del liberalismo político observamos que en ambos casos la tarea fundamental es la de incluir a los excluidos del programa kantiano. Si reparamos en concreto en Hegel y Rawls, máximos representantes del despotismo ilustrado y el liberalismo político, podemos decir que efectivamente comparten una serie de puntos fundamentales: la idea de que una sociedad justa debe asumir el reto del pluralismo, se consideran ambos -aunque cada uno a su modo- herederos del kantismo, ambos intentan reformular el proyecto kantiano con la intención de «incluir» a los excluidos, y para ambos el consenso debe ser definitivo y sólido en lugar de eventual.

Los puntos en común se difuminan por el hecho cierto de que el modo como llevan a cabo tales tareas dista mucho entre sí. Pero no es necesario obviar las diferencias para advertir que, en cualquier caso, ambos están de acuerdo en aspectos nucleares que resumiré como sigue: la observación de que el problema fundamental de la propuesta kantiana, que cada uno intentará resolver a su modo, es que no todas las máximas podrían convertirse en ley (Gesetz) incondicional (unbedingt) del querer, esto es, en máximas queridas por jedes vernünftigen Wesen y que valiesen jederzeit und allgemein, sino sólo aquellas motivaciones donde la libertad al querer se quisiera a sí misma, por lo que ellos pueden llegar a entender como necesario un criterio de inclusión (sobre el que se impusiera un consenso estable y permanente) que diera cuenta de los excluidos.

\section{I.2. EL ORIGEN KANTIANO DE LA IDEA DE LIBERTAD QUE ESTÁ EN JUEGO}

Tanto Rawls como Hegel son herederos de la idea de libertad de Kant. Kant, a su vez, persiste en la vía escotista ${ }^{17}$ que, frente a la concepción intelectualista (según la cual la acción libre es aquella que nace de la aprehensión de lo bueno que mueve a la voluntad necesariamente), considera que lo bueno es lo querido por una voluntad libre (voluntarismo ${ }^{18}$ ), y ello porque piensa la acción libre como aquella que puede querer un número indeterminado o infinito de cosas sin causa intermedia. ${ }^{19}$ Sólo un requisito parecía tener dicho querer: que al querer

16 «As I noted earlier, then, the problem of political liberalism is: How is it possible that there may exist over time a stable and just society of free equal citiziens profundly divided by reasonable religious, philosophical, and moral doctrines?», Political Liberalism, op. cit., XXV.

17 Cfr., García, J.A., «La idea de Dios en Scotto y la metafísica moderna», en Claridades 4 (2012), pp. 91-100.

18 Cfr., Op. ox., I, d,8, q.5, n.24.

19 Cfr., Op. ox. I, d.42, q.1. 
no debería perderse su capacidad para querer cualquier cosa, quiero decir, no debería querer algo que limitara su querer.

Escoto concibe esta libre voluntad como omnipotente. Esta libertad no es libertad para algo, sino para cualquier cosa, y es por ello un principio indeterminado del que Kant acierta a observar un criterio meramente formal al que se ajusta: lo querido puede ser cualquier cosa, y permanecer siendo libre, siempre que al mismo tiempo el fin último querido sea la libertad misma. Aquí se abre una interesantísima cuestión: el querer libre sólo puede darse allí donde se quiere algo, pero no puede consistir en querer ese algo (criterio material), sino que al querer ese algo el fin último fundamental debe ser querer su libertad al querer. $Y$ así, el enemigo fundamental de la libertad era para el ilustrado la influencia o imposición (que reúne interferencia y dominación) cuyo aliado más fuerte era la falta de valor. Kant fue capaz de encontrar sin embargo un tipo peculiar de obligación vor aller Erfahrung ${ }^{20}$ que reposando en una razón a priori garantizaba la libertad. El famoso: Handle so, daß du die Menschheit, sowohl in deiner Person als in der Person eines jeden anderen, jederzeit zugleich als Zweck, niemals bloß als Mittel brauchst.

Hegel, junto con Rawls, considera que ninguna razón debería ser excluida (salvo, insistimos, las que pongan en peligro la libertad misma $^{21}$ ), pero propone una solución, diría, sorprendente: cree en la posibilidad de lo que él mismo denomina una allgemeine Bestimmthet; la cual, de ser posible, tendría algo indudablemente bueno: permitiría no excluir ninguna motivación al tiempo que permitiría que los ciudadanos fueran autónomos. Pero ¿es realmente posible generar un tipo de consenso que asuma todas las razones existentes en conflicto? $\mathrm{O}$ dicho con otras palabras ¿Cabe esperar algún tipo de Aufhebung des Unterschieds $^{22}$ ? Sería desde luego un modo distinto de buscar esa no-exclusión que pretendía Rawls.

Quiero insistir en el dato de que Rawls busca fundamentalmente el mismo propósito que Hegel: que ninguna razón particular sea excluida. A decir verdad, Hegel es aún menos excluyente que Rawls. Quiero decir, si Kant había considerado que no todas las motivaciones tenían cabida en el debate público, lo que ha buscado Hegel es restituir esta exclusión. Cabría preguntarse si verdaderamente era un punto de la propuesta kantiana que se debiera superar. Desde luego, la visión de Hegel tiene cierto sentido: Kant tendría razón salvo que toda motivación fuera en parte racional. La opción à la Rawls es por el contrario construir el overlapping consensus partiendo de eso que Hegel denominó despectivamen-

20 Grundlegung zur... op. cit., p. 408.

21 De ahora en adelante se dará por supuesta esta apostilla.

22 «Die allgemeine Bestimmtheit der empirischen Arten kann nur diese sein, daß sie voneinander verschieden überhaupt sind, ohne entgegengesetzt zu sein», Die Wissenschaft der Logik, op. cit., 6/524. 
te el universal abstracto o abstrakte Allgemeinheit. ${ }^{23}$ ¿Pero es que acaso es posible construir el overlapping consensus partiendo de esa allgemeine Bestimmtheit? ¿?Lo es acaso si partimos de la ignorance sobre las ideas particulares posibles?

\section{DOS CAMINOS DISTINTOS PARA CONSEGUIR EL OVERLAPPING CONSENSUS NO-EXCLUYENTE Y ESTABLE}

A modo de resumen del planteamiento que este trabajo asume como punto de partida: si Kant había observado que la forma de las máximas tenía que ser que al querer cualquier cosa el auténtico fin (Zweck) debía ser siempre die Menschheit que hay en cada uno, ${ }^{24}$ y puesto que Menschheit no designa otra cosa que lo distintivo del ser racional, ${ }^{25}$ lo querido es pues la Autonomie: la capacidad de darse a sí mismo el ser racional su propia ley. Desde este punto de vista la libertad positiva es «la razón» de la libertad negativa (de la no-interferencia). Pero esto también significa que hay motivaciones prácticas que, no cumpliendo este criterio (no teniendo como fin último la libertad), no deberían ser consideradas racionales y, de este modo, deberían ser superadas por otras máximas que sí obedecieran al kategorischer Imperativ.

El caso es que en nuestras sociedades actuales -aunque a decir verdad ha sido así durante toda la historia de la humanidad-convivimos con multitud de ciudadanos que no quieren que su conducta obedezca a un tipo semejante de criterio racional. Diríamos: multitud de personas que no quieren ser «libres» (en sentido ilustrado), que prefieren guiarse por convenciones más o menos arraigadas. Una cuestión que también afecta a nuestros gobernantes cuando establecen discusiones públicas en torno a problemas públicos. El problema cobra especial interés porque aquellos que están llamados a ejercer la razón pública no son elegidos -por supuesto- por su capacidad para establecer diálogos racionales sobre cuestiones de interés público, ${ }^{26}$ ni por su defensa de la libertad positiva como fin último. ¿Qué hacer cuando el ciudadano quiere que decidan por él representantes que no han demostrado, ni parecen ser capaces, de un ejercicio

23 Hegel, G.W.F., Die Wissenschaft der Logik, en G.W.F. Hegel Werke in 20 Bänden Suhrkamp Verlag 1970, 6/392.

24 Handle so, daß du die Menschheit, sowohl in deiner Person als in der Person eines jeden anderen, jederzeit zugleich als Zweck, niemals bloß als Mittel brauchst.

25 Cfr., Die Religion innerhalb der Grenzen der blossen Vernunft, Hegel Werke in 20 Bänden Suhrkamp Verlag 1970, VI27.

26 «los militantes de todos los partidos políticos suspiran por la aparición entre sus filas de un líder con carisma, una especie de mesías que les guíe a la conquista del poder (es decir, ganar el acceso al mejor cargo posible, sin que la personal competencia para el mismo pase de ser algo secundario: ya aprenderemos (...) ¿quién necesita en democracia un líder caristmático?» Carracedo, J. R., Teoría crítica de la ciudadanía democrática, Madrid: Trotta, 2007, pp. 141-142. 
positivo de razón autónoma, sino sólo de una exposición carismática de cierta ideología? El problema no es si el Estado debe decidir entre a) fomentar la capacidad reflexiva (por ejemplo fomentando la enseñanza de la historia de la filosofía $)^{27}$ o b) construir las bases de una sociedad prescindiendo de todas las máximas subjetivas en la discusión en torno a la organización política. El problema es que esta discusión oculta la pregunta siguiente: ¿no deberíamos preferir representantes positivamente libres?

$\mathrm{Y}$ en este caso, ¿qué criterio podríamos establecer para medir si alguien es libre en este sentido positivo? ¿Qué ganaríamos con ello? ¿Perderíamos algo? ¿Al hacer tal cosa estamos promoviendo un ideal particular? ¿Estamos promoviendo en concreto un ideal ilustrado? ¿Estamos excluyendo preferencias de algunas personas que querrían por ejemplo ser gobernadas por alguien que defienda los intereses de una ideología particular? Está claro, por ejemplo, que quien quiera controlar a la opinión popular lo tendrá más fácil si los ciudadanos no son autónomos y se dejan engatusar por mítines fáciles y personalidades carismáticas, ${ }^{28}$ pero ¿no parece aún más grave que ni tan siquiera los propios gobernantes sean incapaces de ejercer una razón autónoma?

\section{II.1. LA PROPUESTA DE HEGEL: \\ UN CONSENSO NO EXCLUYENTE DESDE LA LIBERTAD POSITIVA}

Seguramente la obra de referencia en este caso es aquella obra póstuma que ve la luz en 1837 y que se titula Vorlesungen über die Philosophie der Geschichte. Se trata de la publicación que unos alumnos prepararon a partir de unas lecciones que Hegel impartió entre 1822 y 1831 y que han sido reeditadas en 1840 (reimpresa ésta en 1948), en 1907 y aún en 1917-1920 aparecen editados por Lasson distintos volúmenes de esta obra que, en este proceso de mejora y completitud, ha visto incluso su título inicial transformado, pasándose a llamar: Vorlesungen über die Philosophie der Weltgeschichte. En este proceso de reedición la aspiración ha sido siempre intentar ser fiel al espíritu de aquellas clases que impartió Hegel, cuyo propósito fue mostrar a los alumnos que la historia tenía una dirección, un sentido, su Zweck, y que éste no era otro que la libertad. El impacto, no ya sólo entre los alumnos, sino en el panorama intelectual, fue determinante desde el principio.

En este libro Hegel comenta detalladamente todo un abanico de circunstancias que impiden la situación ideal para que se dé la libertad. Esto puede ocurrir según el alemán allí donde por ejemplo exista un Estado opresor, donde las condiciones climáticas sean extenuantes, o donde se viva en una situación de guerra

27 Heidegger propuso la inhospitalidad como medio para garantizar que el hombre no se acomodara en sus convicciones. Cfr., parágrafos 12 y 40 de $S u Z$ en GA 2.

28 «los italianos, en su grandísima mayoría, sienten que su mayor enemigo es la partitocracia, es decir, los políticos profesionales», El país, 20 de abril de 2000. 
constante. Hegel, en su lección sobre historia, analiza exquisitamente cuáles son esos factores que limitan la libertad, y con gran pasión narra el modo en el que poco a poco la humanidad va haciendo frente a dichas limitaciones en un ejercicio de liberación constante. La historia de la que habla Hegel es la historia de una libertad que se abre paso dialécticamente a través de las limitaciones a las que se ve sometida circunstancialmente. La libertad debe buscarse en lo particular, si bien no para quedarnos en una determinación particular concreta, sino para aprovechar la ocasión de insistir en la Befreiung ${ }^{29}$ gracias a la cual el criterio formal kantiano se va abriendo paso y se le va dando a la realidad material la forma de la libertad. ${ }^{30}$

Debemos observar que si la libertad se ve limitada es porque no está al final, sino que ha estado siempre, aunque nunca de un modo absoluto. La libertad se va realizando a través de las determinaciones en las que se va concretando y dejando atrás. Toda determinación va contra ella, y sin embargo no podríamos buscarla si no fuera precisamente en las determinaciones. Como si cada determinación fuera una huella de la misma; la marca de su paso. Aquí es donde el idealismo se tuerce para aprender a vivir con la paradoja: al mismo tiempo que toda limitación va en contra de la libertad, la libertad sólo puede existir en tensión constante con esa limitación. Si lo indeterminado no puede ser sin relación a la determinación, y siendo sólo en contraste con aquella, la realidad indeterminada sólo existe como resultado de un proceso de realización en el que se niega toda determinación (un negar que no es un rechazar, sino una suerte de neutralización o aufheben).

Tal es la ratio essendi de la dialéctica hegeliana. Esa que Marx nunca llegó a entender, y que viendo que no conducía a ninguna parte la intentó subordinar a un Ende. Con este gesto convertía a la libertad en un ideal determinado que se oponía al que pudieran tener otros, dividiendo a la sociedad como mínimo en dos clases de personas con intereses distintos que luchaban por defenderlos (o lo que es lo mismo, por hacerse con el Estado para hacer que éste se comprometiera con unos intereses particulares). Hegel tenía una concepción de justicia más

29 «Diese Befreiung ist formell, indem die Besonderheit der Zwecke der zugrunde liegende Inhalt bleibt» Hegel, G.W.F., Grundlinien der Philosophie des Rechts, en Werke in 20 Bänden Suhrkamp Verlag 1970, parágrafo 195.

30 «Wir sehen so gegenwärtig die Welt voll vom Prinzip der Freiheit, und dasselbe besonders auf die Staatsverfassung bezogen: diese Prinzipien sind richtig, aber mit dem Formalismus behaftet sind sie Vorurteile, indem die Erkenntnis nicht bis auf den letzten Grund gegangen ist; da allein ist die Versöhnung mit dem schlechthin Substantiellen vorhanden». Hegel G.W.F., Vorlesungen, Werke in 20 Bänden Suhrkamp Verlag 1970, $16 / 243$. 
amplia: extender la libertad a todos los rincones, recogiendo todos los intereses y no sólo los intereses particulares de un grupo. ${ }^{31}$

Ahora bien, Hegel es demasiado pretensioso al considerar que las limitaciones de la libertad son negativas, lo que le impide observar y reconocer que es dicha positividad lo que hace posible el proceso y que es este proceso por ello el que debe constituirse como auténtico objetivo. Es decir, aunque al querer, lo querido (determinado) debe ser la libertad misma (indeterminada) a través de lo particular, ${ }^{32}$ de tal modo que ninguno puede ser pensado sin el otro, ${ }^{33}$ en la filosofia de Hegel lo particular, por parcial, es considerado algo negativo que debe ser superado, y no algo positivo que constituye la realidad del proceso mismo.

\section{II.2. EL FRACASO DE LA PROPUESTA HEGELIANA}

Bien mirado, parece realmente que el idealismo nos sitúa ante un concepto límite que, en la historia se realiza en virtud de cierta Dialektik ${ }^{34}$ aún cuando denn begreifen lässt sich nur Endliches und Bedingtes. ${ }^{35}$ Pero la libertad no debe buscarse sólo allí donde se ha conseguido una reunificación, sino que existe ya en jede Bestimmung. Por eso Schelling corrige con acierto a Hegel y su pretensión de hacer un Superestado comprometido con la libertad. La noción de Estado mismo debe fracasar ${ }^{36}$ precisamente por la ausencia de ese alles. Lo curioso es que también Rawls parece tener como objetivo ese alles, el consenso por superposición. Simplemente rechaza la allgemeine Bestimmtheit como medio viable. Pero si cogemos el testigo de Schelling nos damos cuenta de que pudiera ser que la libertad no tuviera que ver con reunir o incluir, sino con fomentar las diferencias y las discusiones en la medida en que son las diferencias las que garantizan el proceso mismo de Befreigung. Esto que puede sonar en principio

31 Si Hegel no tuviera razón, Rawls es el punto de salvación para devolver la confianza en procesos democráticos y no revolucionarios al presentar la posibilidad de seguir pensando que es posible una unificación no excluyente pensándola, eso así, en términos no absolutos, pero que igualmente evitan la lucha como modo de imposición de unos intereses sobre otros que dejaría a la sociedad dividida en clases en guerra.

32 «die Vernunft des Willens ist eben, sich in der reinen Freiheit zu halten, in allem Besonderen nur sie zu wollen, das Recht nur um des Rechts, die Pflicht nur um der Pflicht willen.» Vorlesungen, op. cit., 12/524.

33 Jacobs W.G., «Filebo, el núcleo de la sabiduría platónica», Contrastes XVI (2011), pp. 397-416, p. 401.

34 «Die Dialektik dagegen ist dies immanente Hinausgehen, worin die Einseitigkeit und Beschränktheit der Verstandesbestimmungen sich als das, was sie ist, nämlich als ihr Negation darstellt. Alles Endliche ist dies, sich selbst aufzuheben», Hegel G.W.F., Enzyklopädie, en Werke in 20 Bänden Suhrkamp Verlag 1970 , paragrafo 81.

35 Jacobs W.G., «Fichtes Gottesanschaung», en Religion und Gott im Denken der Neuzeit, Paderborn: Schöningh, 2000, pp. 99-109, p. 108.

36 Schellling, F.W.J., SPV, en SW VII, p. 462 
provocador, lo explicaré más adelante e intentaré mostrar la interesante vía que se ha abierto recientemente por este camino.

De momento sin embargo quiero decir unas últimas palabras sobre la propuesta de Rawls: la alternativa a Hegel sugerida por Rawls, que nada tiene en cuenta desgraciadamente la filosofía de Schelling, consistirá por su parte en fortalecer aquella condición de vor aller Erfahrung que tenía el principio kantiano.

\section{II.3. RAWLS: UN CONSENSO NO EXCLUYENTE DESDE LA LIBERTAD NEGATIVA}

La intención de Rawls podría ser presentada como el intento de garantizar que aquellos que tienen por función elegir las instituciones de base (aquellas que determinarán el modo como se organizará la vida económica y política de la sociedad) se comprometan con la libertad de los ciudadanos. El método propuesto, en la medida en que parte del desconocimiento de las ideas propias en lo que respecta a la vida buena y a los intereses particulares, garantiza un compromiso real y efectivo con la libertad negativa.

También esta alternativa al despotismo ilustrado plantea problemas. Son clásicas, por ejemplo, las deficiencias destacables del enfoque liberal que han salido a la luz en la discusión constante con otros posicionamientos como el utilitarismo, el libertarismo, el igualitarismo o el comunitarismo. A mí, en particular, la dificultad del modelo liberal que me interesa destacar en este momento es que al afanarse por preservar la capacidad de los ciudadanos a elegir su ideal de vida buena, lo que consiguen es, en el fondo (y precisamente por considerar que este tipo de cuestiones deben ser relegadas a un ámbito privado), favorecer que los ciudadanos se escondan tras un muro infranqueable (su propia casa ${ }^{37}$ ) que les permita vivir sin poner en cuestión dichas convicciones (y en esta medida, estas sociedades promueven ciudadanos incapaces de ejercer una autonomía reflexiva, acostumbrados a que nadie someta a cuestión sus convicciones particulares convirtiéndose en pasto fácil para los movimientos de opinión de masas). $\mathrm{Y}$ en segundo lugar que (dejando a un lado lo que la gente haga en su vida privada) aquellos en quienes hemos cedido la capacidad para decidir sobre instituciones de base, si son incapaces de ejercer una libertad positiva, entonces no podrán evitar ellos mismos las interferencias, puesto que sin la autonomía propia a la que hace referencia la libertad positiva no es posible que se tomen decisiones propias, y en este sentido, no es posible evitar la interferencia.

En consecuencia, si el gobernante no es autónomo, se dará el caso extravagante de que defenderá la no-interferencia quien stricto sensu es interferido. Lo que significa que estaríamos incluyendo en un error de forma: si el gobernante

37 Es muy interesante la apelación de Heidegger a no estar en casa: nicht zu-Hause sein propia de la unheimlich de la que habla en sein und Zeit. 
está comprometido con la no interferencia (lo cual es en sí mismo bueno), pero dicho compromiso no surge de una convicción propia, sino interferida, entonces, y puesto que hemos llegados a este punto de la mano de Kant, es decir, desde el convencimiento de que no debemos fijarnos en lo material (los objetivos concretos), sino en el modo (forma), ¿no estaríamos en última instancia defendiendo lo mismo (aunque con otros nombres) que queríamos evitar? ${ }^{38}$

Claro que, por otro lado, ¿hasta qué punto podemos exigir a alguien que sea libre positivamente, que lleve -dicho heideggerianamente- eine eigene Existenz. Esta pregunta chocaría con las siguientes posibilidades: pudiera darse el caso de que el gobernante no quisiera ser libre positivamente, sino, por ejemplo, portavoz de una ideología. Cabe pensar incluso en el caso ciertamente relevante de que los ciudadanos quisieran libremente (libertad negativa, es decir, sin interferencias $^{39}$ ) ser gobernados por un representante no libre (teniendo libertad ahora el sentido de libertad positiva). Y si tenemos en cuenta que el fundamento de la democracia es respetar la voz de la mayoría, dado el caso de que efectivamente se trate de la decisión de la mayoría (interferida o no, autónoma o no) ¿podemos exigir legítimamente entonces, dadas tales circunstancias, que los representantes deban ser libres positivamente? ${ }^{40}$

El problema es que son muchos los que parecen observar que habría cierta falta de correspondencia entre el ideal de libertad positiva y el respeto por la pluralidad. Se tiene miedo (un miedo impersonal) a que los políticos favorezcan determinadas convicciones particulares y formas de vida concretas si no proceden meramente de un modo procedimental. Es este miedo el que empuja a un liberal a enfocar la cuestión desde puntos de vista meramente pragmáticos, es decir, intentar solucionar los conflictos recurriendo a un criterio meramente procedimental $^{41}$ (prejuicio legalista). Sin embargo todas las decisiones que vayan en la línea de mostrar cómo es posible ser gobernados por representantes no

38 Cfr., Alain Finkielkraut, La défaite de la pensée, París: Gallimard, 1987.

39 Aunque en sentido estricto quien no ejerce positivamente la libertad no puede dejar de ser interferido.

40 En principio pareciera que los ciudadanos no deberían elegir a representantes que sean una mera mueca de una ideología política. Pero lo cierto es que la democracia representativa permite que los ciudadanos no sean libres positivamente. Y son precisamente estos, los ciudadanos no libres (si fueran libres no sería necesaria la representación) los que podrán no querer representantes libres, es decir, representantes que sean críticos y racionales, cuya vocación real sea la libertad. De hecho, como miembros de sociedades liberales, sabemos que ni lo exigen ni lo esperan. Elegimos para que nos gobiernen y representen a quienes piensan con consignas de partidos asumidas como verdades incuestionables en las que han sido formado durante toda sus carreras política más centrada en vender clichés que en aprender a pensar por sí mismos.

41 Cfr., Rosales, J.M. «el coste de la igualdad: una reflexión sobre la cuestión multicultural», en Contrastes Suplemento 5 (2000), 43-56. 
libres positivamente contribuyen a impedir que se exija autonomía a los representantes. Y cada vez que se hace esto, se da un paso atrás respecto a la observación de la necesidad de la libertad positiva, y en esta medida, se ayuda a fomentar la idea de que no es necesario ser libre para gobernar ni decidir sobre cuestiones fundamentales de justicia.

No se trata desde luego que Rawls no quiera que las personas no sean libres positivamente, sino que considera que la única forma razonable de no excluir las decisiones de los demás es limitarse a una libertad como no-interferencia. Según Rawls es lo que querríamos cualquiera de nosotros si estuviéramos en esa posición original ya referida. En lugar de proceder de lo particular, como hizo Hegel, procede de lo desconocido (mediante el recurso del anonimato), por ello pueden darse conflictos con el mundo real ${ }^{42}$ que generan desobediencia civil ${ }^{43}$ pero también la objeción de conciencia, que tiene que ver también con la objeción que nace desde razones prácticas.

Y así, si la razón práctica hacía referencia a principios subjetivos o máximas que adoptamos como guías para nuestras decisiones (y el imperativo categórico no suprime la máxima ni se opone a ella, sino que más bien transforma la máxima en ley moral), la razón pública por su parte (pensemos por ejemplo en los jueces de la Corte Suprema a la hora de interpretar la Constitución) es aquella que decide prescindiendo de las máximas, sometiéndose en su lugar a un proceso de deliberación previamente establecido. Para Kant estaríamos aquí sin duda ante una renuncia a la libertad como autonomía. Pero lo curioso de todo es que el interés de Rawls es precisamente defender la razón práctica: precisamente si los jueces y los políticos actúan ejerciendo una razón pública, entonces los ciudadanos podríamos proceder siguiendo nuestro propio criterio promovido por la razón práctica libre.

En resumen: puesto que Rawls parte del hecho de que existe una pluralidad de razones irreconciliables y opuestas en nuestras sociedades, considera que los políticos y los jueces no deben actuar siguiendo razones prácticas; que esto es algo que deben hacer los ciudadanos, y que sólo lo pueden hacer precisamente allí donde los gobernantes no gobiernan con base a razones prácticas subjetivas. El Estado no puede promover pues máximas concretas, sino garantizar la posibilidad de que los ciudadanos se guíen por sus propias máximas. Si bien habrá ciertamente ciudadanos que no actúen intentando convertir sus máximas en leyes universales, ciudadanos que prefieran someterse a movimientos de masa

42 «Principles of justice are selected unanimously in the original position, but the principles are general in nature, and so we need a mechanism for generating more specific laws in the «real world»», Paul Graham, Rawls, Oxford: GBR, 2006, p. 107.

43 «Civil disobedience arises under conditions in which a partially just society to the «sense of justice» of the majority. In a (fully) just society there would be no need for civil disobedience and in an unjust society there is no sense of justice to which you can appeal», ibid 107. 
ideológicos, de modo que en realidad la condición de posibilidad de la libertad es al mismo tiempo condición de posibilidad de la no-libertad. ${ }^{44}$

\section{II.4. EL FRACASO DE LA PROPUESTA DE RAWLS HEREDADO DE SU REMANENTE IDEALSITA}

¿Fracasa el consenso propuesto por Hegel a partir de la allgemanie Bestimmtheit debido a que existe una pluralidad de razones prácticas irreconciliables y opuestas? Tal es la interpretación de Rawls, y el motivo por el que propone otro procedimiento distinto. Ahora bien, el problema no está en el modo como Hegel quiere lograr ese overlapping consensus, sino en la pretensión misma de que se deba lograr una unificación estable por superposición. Rawls es incapaz de poner en cuestión uno de los distintivos más genuinos del idealismo absoluto de Hegel (que lo diferencia respecto de otras formas de idealismo posibles): el consenso sin fisuras como meta. Y ello porque uno ve el consenso sin fisuras al final y otro al principio, pero en el fondo, en ambos casos dicho consenso es considerado el fundamento del Estado libre.

Lo que busca Rawls frente a Hegel es ver bajo qué otros medios puede realizarse aquel ideal del consenso no-excluyente renunciando a la razón práctica y proponiendo en su lugar una razón limitada. La auténtica superación del idealismo absoluto de Hegel no puede significar sin embargo ver bajo qué otros medios puede realizarse aquel ideal del consenso. El sentido común parece indicar que lo que deberíamos más bien hacer es, sin renunciar a una razón fuerte, ver si no habrá otro tipo de consenso no excluyente que la razón haga posible, aunque no sea el susodicho consenso por superposición.

Sin duda es Schelling un referente mucho más próspero que Rawls al advertir que el resultado de la oposición no debe ser un resultado fijo, sino el proceso mismo. ${ }^{45} \mathrm{Y}$ así, donde el final no es ningún momento último, el mismo proceso se convierte en un movimiento de Befreiung cuyo mayor enemigo es precisamente la fijación (por ser siempre una delimitación). Esta idea, que la retoma Heidegger posteriormente, ${ }^{46}$ es también la que desde Heidegger reclaman Apel y Ricoeur, los representantes de mayor renombre de la hermenéutica actual, para formular una interesante solución al problema aquí tratado. En resumidas cuen-

44 Pensemos, por ejemplo, en un fanático de alguna ideología política que no quiera ser liberado de dicho fanatismo para decidir de manera autónoma a un modo distinto de cómo dictan las opiniones difundidas por sus líderes políticos. No es ya sólo que el Estado permita estas renuncias a la libertad positiva, sino que además se ve claramente que los grupos políticos se favorecen de estas aptitudes para mantenerse en el poder hagan lo que hagan.

45 Leyte, A., Las épocas de Schelling, Madrid: Akal, 1998. p. 14.

46 Cfr., Rojas, A. «El papel de una «apotencia» fundamental en la filosofía tardía de Schelling, y su influencia en la filosofía tardía de Heidegger», Revista de Filosofía 36-2 (2011), pp. 109-131. 
tas lo que buscan es que el hecho del carácter autolegislativo de la libertad pueda mantenerse sin necesidad de esperar un overlapping consensus estable, o mejor dicho: precisamente porque se ha eliminado la pretensión el consenso por superposición.

¿Y qué si no nos ponemos de acuerdo definitivamente? No hay que buscar métodos alternativos (procedimentales) a la argumentación con tal de garantizar el consenso. Si el consenso por superposición fracasa ¿Por qué deberíamos seguir empeñados en un consenso ya vacío? Y sobretodo ¿Cómo se ha podido llegar a pensar que conviene garantizar el consenso renunciando a la argumentación racional (a la razón práctica)? ¿Es que no será más conveniente renunciar al consenso mismo? Debemos pasar ya la época de transición que supone la desconfianza en el logos, no para perseguir los mismos fantasmas idealistasabsolutistas con otros métodos, sino para ser sensatos y entender cuál es el tipo de consenso que la praktische Vernunft hace posible.

Por supuesto, no se trata de renunciar a cualquier tipo de consenso, sino a aquel que se concibe como resultado de un procedimiento de unificación no excluyente. Hay que zafarse ya, Rawls evidentemente no lo hace, de este remanente idealista absoluto que acercan más de lo deseado al filósofo norteamericano a Hegel. Y al zafarnos de dicho remanente nos podremos percatar de que no nos hemos quedado sin consenso ni contrato social, sino de que existe desde luego otra forma de pensar el consenso. Un consensus éventuel ${ }^{47}$ que no se consigue reunificando las posturas enfrentadas y que no aspira a ninguna delimitación definitiva.

\section{UNA ALTERNATIVA BASADA EN LA RECEVABILITÉ III.1. HUIR DEL ESTABLE OVERLAPPING CONSENSUS}

Schelling había propuesto contra Hegel un tipo de relación entre lo indeterminado y lo determinado que no encontraba nunca sosiego, y que sobre todo no lo pretendía, por cuanto que toda determinación era considerada como el cese del poder productivo que emerge de la indeterminación. Pues bien, desde aquí, desde la filosofía de Schelling, y como desarrollaremos más adelante, cabe la posibilidad de pensar que no necesariamente tenemos que considerar el consenso como el fin absolutamente ideal al que tiende el proceso. Desde Schelling, a diferencia de Hegel y Rawls, se abre la posibilidad de pensar un nuevo sentido de la finalidad según la cual el fin no debe significar el ya no más del proceso, en tanto que todo resultado (toda determinación) debe ser entendido como un momento más dentro del proceso que continúa ad infinitum.

47 Cfr., Ricoeur, P., Soi-meme comme un autre, Paris : Éditions du Seuil, p. 336. 
Apel y Ricoeur, por herencia de Heidegger, ${ }^{48}$ recuperan este esquema schellingiano para proponer algo muy interesante: que el consenso debe establecerse mediante un diálogo racional crítico cuya meta no sea el fin del diálogo (que en rigor no se proceda hacia una meta), sino que su fin sea precisamente mantener el diálogo siempre vivo desde el convencimiento de que todo consenso determinado es una limitación del diálogo constituyente. ${ }^{49}$ La manera de mantener vivo el consenso no tiene porqué ser recordar las razones que lo establecieron, como si fueran verdades inamovibles. Tampoco se trata de mantenerlo vivo con la esperanza de que se logre un consenso definitivo (idealismo absoluto de Hegel $^{50}$ ), sino que es posible mantenerlo vivo gracias a su revisión constante. Esta revisión constante ha sido, desgraciadamente y por causa del desconocimiento de la filosofía de Schelling, entendida como la tarea de cuestionar si los derechos deben ser ampliados, pero no se trata de hacer que el consenso sea más o menos abarcador, ${ }^{51}$ es decir, no se trata de buscar cada vez una no-exclusión mayor, sino de aprender a pensarlo éventuel.

\section{III.2. EL CONSENSUS ÉVENTUEL FUNDADO EN LA RECAVABILITÉ}

El consensus éventuel es fruto de una renovada vuelta a la argumentación y a la autonomía que caracterizan la capacidad de autolegislación de la libertad, y supone un renovado compromiso con la pluralidad, ya que busca mantener vivo el diálogo entre posturas enfrentadas: en un diálogo racional (se haya dicho lo que se haya dicho en la historia reciente marcada por la desconfianza de la razón) las convenciones y las tradiciones no son ningún problema, sino condición de posibilidad en tanto que lo que se necesita para que exista diálogo y discusión racional es que haya una pluralidad de razones. El fin, en el sentido de «ya no más», del diálogo racional es tanto la allgemanie Bestimmtheit de Hegel como el overlapping consensu de Rawls, porque en ambos casos se han fijado ya las bases de la sociedad libre. Lo auténticamente libre es sin embargo, pensando la libertad como capacidad autolegislativa, que dicho acuerdo nunca se

48 Cfr., Rojas, A., «El papel de una apotencia fundamental en la filosofía tardía de Schelling y su influencia en la filosofía tardía de Heidegger», Revista de filosofía 36-2 (2011), 109-131.

49 Deberíamos pensar que, si desaparece el diálogo constituyente, desaparecerán también las razones que constituían el consenso. El consenso, de este modo sería el resultado muerto de algo que existió. Un contrato social pasado que ha perdido ya la legitimidad del logos que lo constituye.

50 Para Hegel todo diálogo que no persiga dicha finalidad (la Einheit des Entgegengesetzten) es un diálogo vacío que persigue el único placer de discutir por discutir. Cfr., Vorlesungen Über die Geschichte der Philosophie, en: G.W.F Hegel Werke in zwanzig Bänden, Band 19, Suhrkamp, Frankfurt del meno, 1971, p. 71.

51 Cfr., Rosales, J.M. «el coste de la igualdad: una reflexión sobre la cuestión multicultural», en Contrastes Suplemento 5 (2000), 43-56. 
cierre, que sea siempre eventual, vivo, que esté en continuo proceso constituyente.

Desde luego, toda forma de consenso tiene sus límites, y el proceso de superación de los mismos es la liberación respecto de ellos que tiene en vista siempre la máxima extensión indefinida de la libertad posible. La libertad exige, no un consenso social estable, sino la ruptura del consenso, en base a la cual sólo es posible la discusión y la argumentación. Digamos que la ruptura del consenso (la pluralidad) es necesaria para que haya diálogo y argumentación, entre otras cosas porque discutir con quien no piensa diferente es absurdo. La pluralidad es pues bienvenida: cuanto mayor sea la pluralidad de razones prácticas mejor y más rico será el diálogo, e incluso mejor preparados estaremos para entender que la meta no puede ser ninguna suerte de fijación de un consenso estable, porque «sólo cuando es consciente de sus límites y supuestos, la razón se hace práctica y dialógica.» ${ }^{52}$

Ricoeur ha visto esto con una claridad abrumadora: la argumentación no se opone al conflicto generado por las diferencias, sino que sólo tiene lugar si hay conflicto entre convenciones. L'argumentation s'éprouve dans le conflit des convictions, ${ }^{53}$ porque toda argumentación parte de las convicciones. No debemos olvidar las convicciones. Tampoco aquellas convicciones que se sustentan en convenciones. Lo que debe hacerse es elevar las convicciones al rango de convicciones que puedan ser entendidas por todos en cualquier época (universalizarlas). Aquí estaría el criterio formal: las convictions deben ser elevadas por encima de las conventions de manera que adopten la forma, reconocida por todos, de une vérité posible. ${ }^{54}$

En concreto, lo que propone Ricoeur es la recavabilité: la admisión de una verdad posible como criterio formal. Desde la admisibilidad no se rechaza ninguna convención, todas deben ser traídas a la argumentación, siempre que se le dé la forma para que los que argumentan puedan admitir que se trata de una verdad posible. No se trata de buscar las condiciones que garanticen el consenso, sino las condiciones que garanticen el diálogo. Y para ello lo único que se precisa es que las convicciones vayan más allá de las convenciones para que puedan ser sometidas a discusión y argumentación crítica, o dicho de otra manera: para que haya comunicación real.

Pero entonces lo que se impone es revisar, en la línea de Habermas y Apel, las condiciones de posibilidad de la argumentación crítica. Si fuera posible que nos gobernaran representantes libres (con criterio propio, y no ideológico, capa-

52 Arregui J.V., La pluralidad de la razón, Madrid: Síntesis, 2004, p. 238.

53 Soi-meme comme un autre, op. cit., p. 336.

54 «La voie d'un consensus éventuel ne peut procéder que d'une reconnaissance mutuelle au plan de la recavabilité. C'est-á-dire de l'admission d'une vérité posible, de propositions de sens qui nous sont d'abord étrangères» ibid., p. 336. 
ces de elevar sus convicciones por encima de las convenciones) que llevaran convicciones bien fundadas al diálogo (que el otro podría admitir como una verdad posible) la argumentación abriría un nuevo espacio en el que por fin seríamos gobernados por ciudadanos libres que actuarían, como libres que son, en pos de la libertad de los demás, o dicho de otra manera, desde la consideración de que el fin irrenunciable de cada decisión es la Menscheit.

\section{APEL: LA KOMMUNIKATIVE VERNUNFT}

No podemos quedarnos sólo en la indicación de que el diálogo debe estar basado en la recevabilité. Debemos intentar fundar esta alternativa, mostrando por un lado que es posible, y por otro lado que es preferible, a la hora de intentar construir una sociedad libre. Para mostrar su posibilidad, lo que tendremos que hacer es mostrar las condiciones en las que dicho diálogo resulta eficaz. Y en este sentido habría que decir: que se trata de un diálogo real que se ha desprendido de la consideración de que las convenciones no tienen lugar en una discusión racional, y de la consideración de que hay que establecer un consenso noeventual.

Para hacer frente a estos dos remanentes que aún siguen funcionando en Rawls, Apel propone enfatizar lo que él denomina la Innerlichkeit, ${ }^{55}$ que recuerda a aquella Inheit ${ }^{56}$ de Sein und Zeit. La intención de Apel es clara: hay que evitar desde luego caer en la tentación de querer distanciar el discurso teórico del Universum des menschlichen Diskurs, ${ }^{57}$ pues es indeseable (y quizás imposible) pedir al sujeto (esencialmente incardinado en un mundo) que renuncie a su mundanidad toda vez que se ha descubierto de un modo contundente que el hombre es un ser que está esencialmente en un mundo. ${ }^{58}$ La hermenéutica de la facticidad que hace Heidegger resulta, al menos en este punto (el Dasein como un ser-que-están-en-el-mundo), un hallazgo teórico que la filosofía política debería tener siempre presente. ${ }^{59}$

\footnotetext{
55 Apel K-O., Transformation der Philosophie II, Frankfuert a.M: Suhrkam, 1976., p. 376.

56 Heidegger., M., Seind und Zeit., en GA 2., p. 53.

57 Transformation der Philosophie II, op. cit., p. 392.

58 «In-sein ist demnach der formale existenziale Ausdruck des Seins des Daseins, das die wesenhafte Verfassung des In-der-Welt-seins hat» SuZ, op cit., p. 54.

$59 \mathrm{El}$ problema es que existe aún una creciente línea de investigación que busca demostrar que todas las ideas de SuZ son la expresión filosófica de la ideología nacionalsocialista. Cfr., Quesada, J., «Martin Heidegger y la exigencia política del conocimiento: una raza dura» en Iseogría 43 (2010), 545-563, p. 546. Desde luego, no se trata de una línea mayoritaria, sino aún minoritaria, que no cuenta con el respaldo de los círculos de especialistas en Heidegger. Pero es desde luego una línea que puede poner freno a la posibilidad de hacer una sociedad más libre y mejor en la línea de Apel, en la medida en que tiende a rechazar todo lo que provenga de Heidegger, animando a que se deje de leer al filósofo alemán.
} 
Esta mundanidad es mucho más compleja que la mera indicación comunitarista según la cual nuestra elección de lo bueno está ligada a nuestros vínculos familiares, nacionales o religiosos en los que estamos involucrados desde siempre. La noción de mundanidad dice más bien que el hombre, sin poder dejar de pertenecer al mundo, no pertenece a un mundo del que no se pueda desvincular, sino que aún desvinculándose de éste mundo concreto, siempre que se proyecte y decida lo hará en función de otros mundos posibles. Lo inhumano es pues la original position. Y así, aunque la existencia propia (die eigene Eixistenz) se alcanza en la medida en que es posible abandonar las convenciones (salir a la intemperie abandonando la seguridad del $\mathrm{Zu}$-hause $\operatorname{sein}^{60}$ ), esto no significa que la existencia propia salga fuera de todo mundo, sino que se trata de la posibilidad de proyectar mundos posibles.

Pues bien, Apel, magnífico conocedor de Heidegger, aprovecha magistralmente esto para decir que el hombre debe abandonar el mundo en el que se encuentra caído para generar un nuevo mundo que él piensa en los términos de una Kommunikationsgesellschaff, ${ }^{61}$ la cual definiríamos como aquella dentro de la cual cabe la comunicación entre sujetos diferentes que parten de convicciones diferentes. Dicha sociedad de la comunicación no se conseguirá mediante criterios objetivos (al modo como ocurre en las ciencias) que prescindieran de las convenciones, sino ejerciendo cierta transformación sobre ellas: el uso público de la razón exige que tales convenciones sean reformuladas hasta ser presentadas como convicciones no dependientes de convenciones, sino fundadas en la propia argumentación racional, de modo que puedan ser consideradas como verdades posibles por cualquier sujeto racional siguiendo el criterio que habíamos propuesto en el parágrafo anterior a través de la idea de recevabilité de Ricoeur.

Esta sociedad de la comunicación estaría constituida sin renunciar a ninguna experiencia propia, sino que se construiría en la medida en que los Argumentierenden fueran capaces de elevarla por encima de las convenciones hasta darle un sentido universal que haga que cualquiera pueda entender lo que se dice como una verdad posible. Y así, para Apel, es posible establecer las condiciones de una Kritischen Kommunikation que se basara en la pretensión de universalidad, es decir, exponiendo las argumentaciones de manera que resulten comprensibles por cualquiera en cualquier época.

Esta Sprachgemeinschaft ${ }^{62}$ no sólo es posible, sino que es realista en lugar de ficticia o idealista como ocurre respectivamente con el overlapping consensus de

60 Sein und Zeit op. cit $\mathrm{p} .188$.

61 Transformation der Philosophie II, op. cit., p., 401.

62 Transformation der Philosophie II, op. cit., p. 423. 
Rawls y la allgemeine Bestimmtheit de Hegel. ${ }^{63}$ Estas dos últimas son más bien idealizaciones que funcionan como criterio utópico. Lo que propone Apel, en el fondo, es lo que de hecho hacen las personas racionales cuando quieren dialogar: dan por hecho que todo lo que se expone racionalmente lo puede comprender cualquier ser racional.

El contenido de este diálogo es también real: pretensiones concretas atribuibles a un lugar y a un tiempo determinados. Se trata simplemente de ser expuestas de tal modo que no dependan de ninguna asunción, sino que toda conclusión debe seguirse del propio discurso argumentativo. Es por ello justamente que podrá ser seguido por cualquier sujeto racional en cualquier época. Lo cual no mengua en ningún momento su carácter situacional, ${ }^{64}$ ya que el hecho de que pueda ser entendida por cualquiera no significa que no sea una propuesta sólo comprensible hermenéuticamente en un aquí y un ahora concretos.

Siguiendo esta propuesta la opinión llega a ser pública de un modo muy propio: se trata de la apertura del juicio, pues hacer público es siempre un modo propio de abrir algo a los demás, veröffentlichen. Poco tiene esta razón que ver con la public reason que renuncia a la discusión real para generar una discusión imaginaria. La razón no debe ser pública, sino comunicativa; debe ser una kommunikative Vernunf, bien entendido que la razón comunicativa es la que se abre al público. Estamos acostumbrados a una política de eslóganes y mítines, donde los representantes se han convertido en el mayor enemigo de la democracia. ${ }^{65} \mathrm{La}$ solución que propongo con apoyo en Apel y Ricoeur es decisiva, a mi juicio, para revitalizar nuestras instituciones democráticas de base.

Por mencionar algún inconveniente que se ha puesto para creer en la posibilidad de dicho consenso, recogeré la crítica de Habermas, quien considera que cuando intentamos la Rationalisierung von Lebenswelten nos encontramos con los siguientes tres componentes: una cultura, una sociedad y una personalidad. ${ }^{66}$ Componentes que designan o dan lugar a lo que denominaríamos las Lebensformen o incluso las Lebensgeschichten. La idea de Habermas es que esto no se puede sin más universalizar. Habermas es contundente y dice que no se puede

63 Cfr., Rojas, A., «La imaginación en la filosofía de Hegel», en Contrastes suplemento 15 (2010) 275-283.

64 Se piensa de una manera rejuvenecida la relación entre universalidad e historicidad.

65 «cualquiera que haya presenciado un debate entre políticos de partido sobre cualquier cuestión observa pronto que allí no se debate libremente, sino que cada participante se limita a defender los puntos de vista de su partido (iy ay si no lo hace así!), que sus opiniones son perfectamente previsibles. Su ideario, pues, es bastante fijo. De lo que se discute en los partidos es sobre la estrategia que se ha de seguir, con sus tácticas ocasionales; pero esta discusión la hace la cúpula burocrática. Los demás son gusanos votantes. Pero gusanos disciplinados (con alguna excepción), que esperan pacientemente su acceso (o reposición) a las listas de candidatos y a los cargos políticos. Su actitud es la que permite cerrar el ciclo de la oligarquización», Teoría crítica de la ciudadanía democrática, op. cit., p. 150.

66 Habermas, J., Erläuterungen zur Diskursethik, Frankfurt a.M: Suhrkamp, 1992, p. 45. 
universalizar por suerte. ${ }^{67} \mathrm{Si}$ fuera así la universalización no podría considerarse, como ocurría con la praktische Vernunft, como una fuente de normas y criterios de conducta. ${ }^{68}$

Desde luego no le falta razón, pero es que a mi modo de ver no se trata de racionalizar las formas de vida, ya que, y en este punto quiero volver al principio, no estamos discutiendo sólo sobre cómo debemos comportarnos los ciudadanos, sino cuál debe de ser la regla principal de un diálogo racional, como el que deberá tener lugar allí donde los representantes deben hacer un uso público de la razón.

Desde este punto de vista, no se trata sólo de educar a la ciudadanía en la razón comunicativa, sino sobre todo a la clase representativa de la ciudadanía. Es a ellos a quienes les debemos exigir estar a la altura de una sociedad libre. Es en ellos sobre quienes debe caer todo el peso del Estado para educarlos en su ejercicio público de la razón. Especialmente cuando estamos acostumbrados a que en la política reciente los políticos entiendan por diálogo la mera expresión por turnos de ideologías que se consideran dogmas de partido. A lo máximo a lo que llegan es a pretender acuerdos negociando e intercambiando intereses. Se necesitan políticos comprometidos con la argumentación crítica que permita la comunicación real, y el debate auténtico y necesario que en muchos casos España sigue aplazando. A los gobernantes debemos exigirles que formen parte de esta comunidad de comunicación en la cual sólo pueden tener lugar argumentaciones que puedan ser asumidas por todo ser racional. Ya que estos representantes serían de este modo verdaderamente libres, autónomos, y podrían estar comprometidos auténticamente con la libertad y su extensión a toda la ciudadanía. Pues como dice Schelling: «sólo el que ha degustado [gekostet] la libertad puede sentir el deseo de hacer que todo la iguale, de extenderla por todo el universo». ${ }^{69}$

AlejandRo Rojas es profesor de filosofía en el Malaga Institute of Technology, presidente de FICUM (Asociación para la promoción de la Filosofía y la Cultura en Málaga) y miembro del grupo de investigación sobre el idealismo alemán y sus consecuencias actuales, en la Universidad de Málaga.

Líneas de investigación:

Heidegger, Schelling, Platón, hermenéutica, idealismo alemán, teorías de la verdad.

\section{Publicaciones recientes:}

2014: «Die Idee des Potnezlosen in der Spätphilosophie Schellings und in der Spätphilosophie Heideggers», Philosophisches Jahrbuch 121, I (2014), 92-110.

2012: «la ciudad inhóspita promovida por Heidegger», Isegoría 47 (2012), 499-517.

Dirección electrónica: Alejandro@filosofiaenmalaga.net

67 Ibid., p. 48.

68 Ibid., p. 191.

$69 \mathrm{PhU}, \mathrm{SW}$ VII, 351. 